\title{
Full-Length Genomic Sequence of Bovine Coronavirus (31kb)
}

\author{
Completion of the open reading frame $1 a / 1 b$ sequences
}

\author{
DONGWAN YOO* and YANLONG PEI
}

Department of Pathobiology, Ontario Veterinary College, University of Guelph, Ontario

NIG 2Wl Canada. *Corresponding author: Email:dyoo@uoguelph.ca

\section{INTRODUCTION}

Bovine coronavirus $(\mathrm{BCV})$ is an important veterinary pathogen which causes neonatal diarrhea in newborn calves and winter dysentery in adult cattle. Recent studies indicate that $\mathrm{BCV}$ also infects the respiratory tract of cattle producing severe respiratory problems, especially in feedlot cattle. $\mathrm{BCV}$ belongs to the antigenic group II of coronaviruses and shares the antigenic and genetic similarities with mouse hepatitis virus (MHV), human coronavirus strain $\mathrm{OC} 43$, turkey coronavirus, and hemagglutinating encephalomyelitis virus of pigs. Approximately $10 \mathrm{~kb}$ of the 3' most BCV genome has been sequenced, and this region is known to encode all the structural proteins plus the $32 \mathrm{k}$ nonstructural protein which resides immediately upstream of the hemagglutinin-esterase (HE) glycoprotein gene. The comparative studies indicate that the genome organization of $\mathrm{BCV}$ is similar to but distinct from MHV. In BCV, the HE gene is functional coding for a major envelop protein while it is an optional gene in MHV. Similarly, the $32 \mathrm{k}$ protein gene is absent in some of the MHV variants. The region between the spike (S) protein gene and the small membrane (E) protein gene also shows a significant sequence divergence among coronaviruses. Two thirds of the BCV genome remain largely undetermined.

To date, coronaviruses of which the full length genomic sequences are available include mouse hepatitis virus (MHV) (Bredenbeek et al, 1990; Lee etal, 1991; Bonilla et al, 1994), human coronavirus 229E (Herold et al,

The Nidoviruses (Coronaviruses and Arteriviruses).

Edited by Ehud Lavi et al., Kluwer Academic/Plenum Publishers. 2001. 
1994), porcine transmissible gastroenteritis virus (TGEV) (Almazan et al, 2000), and avian infectious bronchitis virus (IBV) (Boursnell et al 1987). Of these viruses, human coronavirus $229 \mathrm{E}$ and TGEV fall within the same antigenic group (group I), and IBV is a group III virus. In the antigenic group II which $\mathrm{BCV}$ belongs to, MHV is the only virus that the full-length sequence has been determined. My laboratory has recently completed sequencing of the entire genome of $\mathrm{BCV}$, and in this report we present the structural organization of the $\mathrm{BCV}$ genome.

\section{MATERIALS AND METHODS}

\section{$2.1 \quad$ cDNA Cloning}

The Quebec strain of $\mathrm{BCV}$ was propagated in Mardin-Darby bovine kidney (MDBK) cells. Genomic RNA was prepared from the purified virions, and double stranded cDNA was synthesized by standard methods. After addition of Bam HI linkers, cDNAs were ligated into the Bam HI site of pTZ19R and used transform E. coli strain DH1. Specific clones were identified by colony hybridization using a ${ }^{32} \mathrm{P}$-labeled cDNA probe prepared by randomly primed reverse transcription of viral genomic RNA or by PCR. For RT-PCR, total cellular RNA was extracted from virus-infected cells using Trizol and used as a template for cDNA synthesis.

\subsection{Reverse Transcription Polymerase Chain Reaction}

For first-stranded cDNA synthesis, Superscript II RNase H Negative Reverse Transcriptase (GIBCO BRL) was used. The first strand cDNA was PCR-amplified using Vent DNA polymerase (New England Biolab) in GeneAmp Thermocycler PE2400 (Perkin Elmer).

\subsection{DNA Sequencing}

The nucleotide sequences were determined either by manual sequencing or BY using an automated DNA sequencer. For manual sequencing, a series of overlapping clones were generated and the overlapping clones were sequenced using universal primers. For automated sequencing, new primers were generated based on the determined sequence to walk along the unsequenced region. Sequences were assembled and analyzed using the GCG Wisconsin sequence analysis package. The sequence has been deposited to the GenBank database under accession number AF220295. 


\section{RESULTS AND DISCUSSION}

The overlapping sequences were assembled as a single contiguous sequence to represent the full-length genomic sequence of $\mathrm{BCV}$. The $\mathrm{BCV}$ genome appeared to comprise of 31043 nucleotides, excluding the 3' terminal polyadenylation tail. The BCV sequence was 291 nucleotides shorter than the genome of MHV A59, and the two viruses shared an overall $71 \%$ sequence identity at the nucleotides level of the full-length genome. Open reading frame la (ORF1a) was able to code for a polypeptide of 4383 amino acids. ORFla and $1 \mathrm{~b}$ overlapped by 28 nucleotides, and this overlap was significantly shorter than that of MHV A59. A slippery sequence was identified within the overlapping region suggesting that a $1 \mathrm{a} / 1 \mathrm{~b}$ fusion protein of 7061 amino acids would be produced (Figure 1).

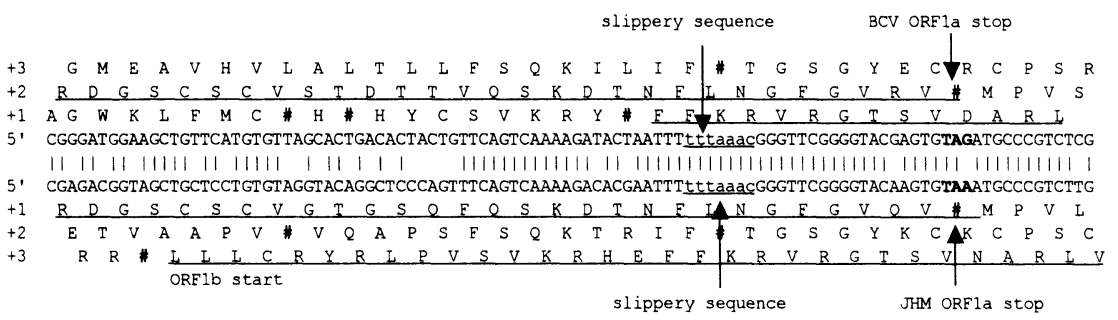

Figure 1. Sequence comparison of the ORFla/ORFlb ribosomal frame shifting region of $\mathrm{BCV}$ and MHV JHM. Slippery sequences are illustrated in lower case and indicated by arrows. Stop codons for ORF1a (TAG for BCV and TAA for JHM) are depicted in boldface and indicated by arrow. Frames are indicated in numbers, and amino acid sequences encoded in the open reading frames $1 \mathrm{a}$ and $\mathrm{lb}$ are underlined.

The BCV full-length genomic sequence was compared with that of other coronaviruses (Table 1). The BCV genome exhibited the highest sequence homology with the genome of MHV A59 (70.8\%), but the homologies were only $48.3 \%, 52.5 \%$, and $53 \%$, when compared with IBV, HCV $229 \mathrm{E}$, and TGEV, respectively. The $1 \mathrm{a} / 1 \mathrm{~b}$ polyprotein of $\mathrm{BCV}$ retained a similar level of amino acid identity to that of A59 (72.9\%). The 1a sequence diversed more with only $68 \%$ homology while the $1 \mathrm{~b}$ homology was $86 \%$. The sequence conservation of the $1 \mathrm{a} / 1 \mathrm{~b}$ polyprotein was low in IBV, 229E, and TGEV, with an overall homology of only $36 \%$ (Table 1). Nevertheless, all the putative functional domains that were identified in all other coronaviruses were found to have been conserved in $\mathrm{BCV}$, including the motifs for two separate papain-like cysteine proteinases, a 3C-like chymotrypsin proteinase, a cysteine rich murine growth factor-like, a RNA dependent RNA polymerase, a zinc finger-like, and a helicase. 
Putative proteolytic cleavage sites specific for the papain-like proteinase were predicted at $\mathrm{RG} 246 / \mathrm{V}$ and A851/G. In addition to these sites, 11 additional cleavage sites ( 9 sites in la and 4 sites in $1 \mathrm{~b}$ ) were identified as potential catalytic sites for 3C-like proteinase: Q3247/S, Q3549S, Q3836/S, Q3928/S. Q4122/N, Q4232/A, Q4369/S, Q5299/S, Q5902/C, Q6423/S, and Q6792/A.

Table 1. Sequence identities of the BCV genome with other coronaviruses

\begin{tabular}{lcc}
\hline Virus & Full genomic sequence $(\mathrm{nts})$ & $\mathrm{la} / \mathrm{lb}$ fusion protein sequence (aa) \\
\hline MHV A59 & $70.8 \%$ & $72.9 \%$ \\
TGEV & $53.0 \%$ & $36.4 \%$ \\
HCV 229E & $52.5 \%$ & $35.7 \%$ \\
IBV & $48.3 \%$ & $36.5 \%$ \\
\hline
\end{tabular}

\section{ACKNOWLEDGMENTS}

Authors are grateful to Drs. M. D. Parker and G. J. Cox for their contribution in completing this sequence. We thank Dr. E. J. Snijder for his help with predictions of the proteolytic cleavage sites of the ORF1a and $1 \mathrm{~b}$ proteins. This research was supported by Medical Research Council of Canada.

\section{REFERENCES}

Almazan, F., Gonzalez, J. M., Penzes, Z., Izeta, A., Calvo, E., Plana_Duran, J., and Enjuanes, L. 2000. Proc. Natl. Acad. Sci. U.S.A. 97, 5516_5521.

Bonilla, P. J., Gorbalenya, A. E. and Weiss, S. R. 1994. Virology 198, 736-740.

Boursnell, M. E., Brown, T. D., Foulds, I. J., Green, P. F., Tomley, F. M. and Binns, M. M. 1987. J. Gen. Virol. 68, 57-77.

Bredenbeek, P. J., Pachuk, C. J., Noten, A. F., Charite, J., Luytjes, W., Weiss, S. R. and Spaan, W. J. 1990. Nucl. Acids Res. 18, 1825-1832.

Herold, J., Raabe, T., Schelle_Prinz, B. and Siddell, S. G. 1993. Virology 195, 680-691.

Lee, H. J., Shieh, C. K., Gorbalenya, A. E., Koonin, E. V., La Monica, N., Tuler, J.,

Bagdzhardzhyan, A. and Lai, M. M. C. 1991. Virology 180, 567-582.

Storz, J., Stine, L., Liem, A., Anderson, G. A. 1996. J. Am. Vet. Med. Assoc. 208:14521455. 